\title{
El reforzamiento de las relaciones franco-peruanas en el campo de la diplomacia económica (1945-1975)*
}

\author{
Getsiva Cayo Durand de Geist**
}

\section{RESUMEN}

Recientemente el estudio de las relaciones internacionales invita a explorar campos cada vez más innovadores. Los investigadores son cada vez más atraídos por el rol importante que la "diplomacia económica» ha jugado para el desarrollo y la expansión económica de los Estados. El ejemplo de la diplomacia económica franco-peruana ha puesto en cuestión los elementos estratégicos que influyeron en su acercamiento bilateral. Este artículo propone examinar los actores, las funciones, los roles de los instrumentos institucionales y los ejes de apoyo que han interactuado bajo la política económica de cada país entre 1945-1975. $\mathrm{Al}$ respecto, fue posible identificar que la estructura de la diplomacia económica en ambas naciones estuvo sujeta a métodos similares pero a su vez contrastados. Por una parte, Francia apostó por la expansión y la especialización de su cuerpo diplomático con el fin de volver aún más activo el rol de su diplomacia económica. Por otra parte, debido a factores políticos y económicos, el rol de la diplomacia económica peruana fue más pasiva al estar en la búsqueda de nuevas inversiones extranjeras.

Palabras clave: Relaciones internacionales, diplomacia económica, Francia, Perú, política económica exterior, relaciones franco-peruanas, 1945-1975

\footnotetext{
* El presente artículo es el resumen de un capítulo de la tesis doctoral en preparación: Las relaciones económicas, financieras y comerciales entre el Perú y Francia. 1945-1975. El capítulo V trata sobre "El estrechamiento de las relaciones diplomáticas y económicas entre Francia y Perú ». Tesis preparada bajo la dirección de Dominique Barjot y la asesoría de Fabián Novak.

** Historiadora, magíster en Historia Contemporánea, doctoranda afiliada al Centro Roland Mousnier de la Universidad París-Sorbona IV, Francia. Correo electrónico: getsiva.cayo@posteo.de
} 
Economic diplomacy and the strengthening of the foreign relations between Peru and France (1945-1975)

\section{Abstract}

In recent times, the study of international relations began to explore new areas of research and to invent innovative approaches. Scholars turned their attention to the role of "economic diplomacy" as an important mean of foreign policy in fostering economic development and expansion. The case of the franco-peruvian economic diplomacy allows analyzing different structures and strategies which were directed towards a bilateral rapprochement. This paper studies the actors, functions and the institutional framework of the foreign economic policy of France and Peru between 1945 and 1975. In a comparative perspective, it is thereby possible to identify, a part of structural similarities, two clearly contrasting strategies in their economic diplomacy. On the one hand, France invested in the extending and specializing of their diplomatic staff in order to implement an active economic diplomacy. On the other hand, due to political and financial reasons, Peru often remained in a more passive role in the search for foreign investments.

Keywords: International relations, economic diplomacy, France, Peru, foreign economic policy, franco-peruvian relations, 1945-1975 


\section{Introducción}

Depuis mon arrivée au Pérou, je me suis efforcé de trouver le moyen qui permettrait à la France de prendre une place plus importante parmi les fournisseurs de ce pays. Après quelque mois de séjours je suis obligé de reconnaître la difficulté de la tâche et d'admettre que seul, et de loin, je ne suis pas en mesure d'agir utilement. La collaboration des industries françaises est nécessaire ainsi que l'appui de votre Direction et des Affaires Etrangères [... $]^{1}$.

El Plan Marshall apresuró el proceso de reconstrucción de la economía francesa y por ende este país dio inicio a un período de crecimiento económico ininterrumpido. Esos treinta años fueron nombrados como los Trente Glorieuses (1946-1975) por el historiador francés Jean Fourastié (1979). El crecimiento económico constante no solo se experimentó en ese país. La mayoría de economías industrializadas atravesó por una etapa similar. ¿Qué sucedió con los países en vías de desarrollo? ¿El Perú fue beneficiado durante estas tres décadas de boom económico?

El fin de la Segunda Guerra mundial inauguró una nueva era en el campo de las relaciones económicas internacionales. La americanización entrañó una lucha de influencias de todo orden, pero sobre todo en el dominio económico (Barjot, Lescent-Giles y De Ferriere Le Vayer, 2002). En medio de la guerra fría, la confrontación ideológica también se reflejó en el plano económico. La competencia global tomó un fuerte impulso. Paralelamente, el proceso de descolonización acarreó la emergencia de un nuevo bloque de países bajo la denominación de «tercer mundo». En ese contexto, las influencias económicas invitan a reflexionar sobre los actores que interactúan a favor de éstas. Incitan a conocer más sobre los campos de acción que ejercieron funciones directas para la expansión económica de determinados países. Tal análisis es necesario para conocer el grado de dependencia existente entre los Estados y el mundo de las empresas tanto al interior como al exterior de un país. La diplomacia económica viene a ser entonces el principal instrumento representado en el exterior encargado de defender y de promover los intereses económicos de una nación.

En el presente artículo, se ha optado por estudiar las relaciones bilaterales francoperuanas en el campo de la diplomacia económica. ¿Cómo estuvo representada institucionalmente la diplomacia económica de Francia y de Perú en el exterior entre 1945-1975? ¿Cuáles fueron los organismos bilaterales que fomentaron un acercamiento de sus relaciones en esta materia? ¿Cuáles fueron los instrumentos de apoyo para tal misión? Primeramente se formulará un concepto básico de la diplomacia económica para comprender la perspectiva focalizada en este estudio. En un segundo

\footnotetext{
«Développement des ventes françaises au Pérou. Ouverture d'un comptoir», lettre n 416, Ambassade de France au Pérou, B-95-1 Amérique, Pérou (14), Questions économiques 1944-1952, Archives MAE, Lima, 6 de febrero de 1950, pp. 1-2.
} 
punto, se tratará de definir la estructura de la diplomacia económica en Francia y en el Perú bajo una óptica individual. En un tercer momento, los ejes institucionales de la diplomacia económica franco-peruana serán abordados. Para tal objetivo se propuso un primer análisis de algunos actores que jugaron un rol importante bajo el ejemplo de las embajadas y las cámaras de comercio. Por último, se tratará de determinar algunos instrumentos de apoyo que colaboraron directamente para el reforzamiento de la diplomacia económica franco-peruana. Al respecto, los acuerdos financieros franco-peruanos, una Feria de Exposición francesa en Lima y dos visitas presidenciales podrán enmarcar la acción de dos países en el seno de las relaciones Norte-Sur.

\section{Definición de la diplomacia económica: un primer enfoque}

El estudio de las relaciones diplomáticas bilaterales abre un abanico de preguntas en diversos campos interdisciplinarios. Este artículo propone concentrarse en el ámbito de la diplomacia económica de manera introductoria. De hecho, cabe notar que este dominio, y más precisamente el de la diplomacia comercial, tomaron una mayor importancia solo durante las últimas décadas. J. Morillas define la diplomacia económica como la utilización de la capacidad de influencia política de los Estados a favor de sus intereses económicos en los mercados internacionales. Esta negocia la libertad de exportar y de invertir más allá de las fronteras nacionales y actúa junto a las empresas que trabajan en el extranjero (2000, p. 41).

Si se toma en cuenta cuán prioritarios son los fines económicos para las naciones, entonces puede afirmarse que la diplomacia económica se ha convertido en un instrumento fundamental para el crecimiento y desarrollo tan deseado. Guy Carron (1998) enfatiza que la diplomacia económica no ha remplazado a la diplomacia política, no obstante, esta se ha convertido en su complemento inseparable. A pesar de tratarse de conceptos desarrollados recientemente, los Estados y sus instituciones pertinentes ya han venido desempeñando las funciones competentes en este campo sin haber, a lo mejor, tomado conciencia plena de su puesta en práctica. Conceptualizada o preconceptualizada, la diplomacia económica ha tomado una posición tajante poco antes del fin de la Segunda Guerra Mundial.

Pedro Sánchez enfatiza que como fruto de la globalización, las actividades tradicionales diplomáticas que giraban en torno a la cooperación política internacional, la seguridad y el mantenimiento de la paz, han sido desplazadas cada vez más por la defensa de los intereses económicos (Sánchez Castejón, 2013, pp. 345-362). Ciertamente los intereses económicos, articulados de manera oficial o no formal, siempre han existido. Sin embargo, la institucionalización de estructuras diplomáticas y su buen funcionamiento han servido cada vez más al desarrollo de los intereses 
comerciales y económicos. De esta manera, el periodo de los Trente Glorieuses se muestra como un escenario muy pertinente para el estudio de la diplomacia económica. Durante estos ańos, la intensificación de la competencia económica no solo fue el motor del desarrollo económico de una nueva era. Esta también originó, sobre todo en los países industrializados, toda una política de expansión económica a gran escala. En contraste, la gran mayoría de los países en vías de desarrollo tuvieron un rol más pasivo. Ellos más bien fueron los grandes receptores de políticas de expansión, económicas y financieras. De influencias geopolíticas se pasó a influencias económicas donde el «poder blando» y el "poder duro» también jugaron su rol (Nye, 2004). ¿Acaso bajo el ejemplo de la diplomacia económica franco-peruana se podrían diferenciar tales actores e influencias?

Los actores más importantes a señalar fueron, en primera instancia, los altos funcionarios y los diplomáticos. Los ministros, los embajadores, agregados y consejeros comerciales o financieros cumplieron sus funciones de acuerdo a sus exigencias y posibilidades. Funciones encomendadas desde sus ministerios, los cuales a su vez proporcionaron los medios necesarios para llevarlas a cabo. No obstante, los hombres de negocios y los empresarios fueron también quienes aportaron enormemente al desarrollo y buen funcionamiento de las misiones económicas. La estructura del cuerpo diplomático en el ámbito económico tanto de Francia como de Perú son dos ejemplos interesantes a tratar.

Este estudio no pretende hacer un análisis comparativo de dos países disímiles en cuanto a su cultura, geógrafa o su desarrollo económico. Empero, el hecho de poner en cuestión las actividades de sus respectivos órganos diplomáticos ha permitido comprender desde otra perspectiva la política exterior de cada país. En ese sentido, este análisis propone conocer más a fondo el intento o la búsqueda de las políticas económicas y comerciales. Se incide en los términos intento o búsqueda porque en determinadas etapas, la política exterior tanto del Perú como la de Francia no fueron definidas de manera precisa. Es así que, los funcionarios y diplomáticos, unos más preparados que otros, junto con los empresarios, unos más emprendedores que otros, cumplieron sus respectivas tareas. La labor de estas personas se sumó al trabajo de instituciones y empresas públicas o privadas. Estos actores operaron bajo intereses estatales o particulares supervisados por sus gobiernos y autoridades. Por ende, la diplomacia económica jugó y juega un rol importante a escala multilateral y bilateral.

\section{Estructura y alineamiento de la diplomacia económica en Francia y en el Perú}

Es cierto que el Estado juega un rol altamente valioso en el campo de la diplomacia económica. En el caso de Francia este hecho se ejemplificó puntualmente. L. Badel 
afirma que desde 1945 la conquista de los mercados exteriores para este país ha estado apoyada en una estructura administrativa sólida. Una serie de instrumentos públicos y parapúblicos velaron por el cumplimiento de una diplomacia comercial francesa cada vez más afinada ${ }^{2}$. Cabe recordar que a medida que los países latinoamericanos se fueron emancipando del yugo español, la nación francesa se propuso acrecentar su influencia económica. Esta veló por un crecimiento del flujo de sus intercambios con las recientes naciones latinoamericanas junto con sus influencias culturales y militares (Novak, 2005, pp. 30-32). Después de la Segunda Guerra Mundial, Francia empezó a reactivar su interés por sus socios comerciales a quienes no pudo abastecer durante el conflicto. La Comisión del Ministerio de Información comenzó a organizar sus oficinas en todo América latina desde 1945. El Ministerio de Aeronáutica envió sus misiones al Perú desde 1946. Los dos instrumentos principales fueron: los financiamientos privilegiados y la cooperación técnica. El Gobierno francés trabajó ininterrumpidamente bajo ese modelo hasta mediados de la década de 1970. Baudel explica que la diplomacia comercial francesa es producto de una mezcla de su propia política exterior. Ambiciones sobre la influencia cultural, militar y técnica, pero también ambiciones estratégicas como el hecho de crear "puentes» con los países socialistas así como la obligación de velar por el desarrollo económico (Badel, 2010, pp. 9-11).

De hecho una vez iniciada la guerra fría, Francia se mostró como una potencia mundial neutral o más precisamente como una «tercera vía» entre los Estados Unidos y la Unión Soviética. Por otro lado, el talón de Aquiles de esta estructura estuvo concentrado en la política de cooperación económica francesa. Esta estuvo extremadamente focalizada en sus excolonias de África negra o subsahariana o de Magreb en la década de 1960. Sin embargo, a pesar de la lenta reacción ante los «mercados protegidos», la expansión económica francesa no ignoró del todo al continente latinoamericano. Si bien es cierto, esta región no fue una prioridad para Francia por múltiples factores, este subcontinente no fue dejado de lado. La investigación en los archivos tanto públicos como privados en París ha corroborado esta hipótesis.

Por otra parte, el Estado peruano jugó un rol menor en la elaboración de una política económica planificada. Por lo tanto, la diplomacia económica fue también un instrumento de desarrollo económico desatendido. La posición de la política económica del Perú durante los Trente Glorieuses ha estado totalmente ligada al péndulo político y sus respectivos gobernantes. Como lo subraya J. Sheahan, el motor del crecimiento

\footnotetext{
2 La Dirección de Relaciones Económicas Exteriores (DREE) creada en 1944, el cuerpo de la Expansión Económica (ENA) creada en 1945, la Compañía Francesa de Seguros para el Comercio Exterior (COFACE) creada en 1946 se sumaron a las labores del Ministerio de Asuntos Exteriores más conocido como el Quay d'Orsay (Badel, 2010, p. 8).
} 
económico peruano se ha basado en el desarrollo de las exportaciones de productos primarios. No obstante, la inversión extranjera ha tomado cada vez mayor importancia a lo largo del siglo XX. Así, hasta mediados de la década de 1970 el Perú se caracterizó por ser una economía abierta (2001, pp. 70-74).

Thorp y Bertram precisan que los gobiernos peruanos no estuvieron preparados para negociar con compañias extranjeras y por el contrario se produjo una reducción de la capacidad empresarial. Sucesivamente, la dependencia de recursos externos se acentuó cada vez más. Así, hasta 1968, fecha donde se puso en marcha el intervencionismo de Estado, el rol que jugaron las empresas extranjeras y de las exportaciones en la economía peruana fue de una importancia exagerada (2013, pp. 399-401). En efecto, durante el periodo estudiado se pudo notar que, a pesar de las resistencias y descontentos sociales, el Perú mantuvo una postura firme en pro de un modelo económico liberal entre 1945 y 1968. Por supuesto, no faltaron etapas en las que se tuvo que frenar o moderar las políticas liberales. Odría y su politica pro-americana se opuso al segundo mandato de Manuel Prado, esta vez pro-europeo. A pesar de ello ambos gobernantes continuaron con el objetivo de acrecentar inversiones extranjeras.

Sin embargo, el proyecto de acercamiento transatlántico y las medidas en materia de diplomacia económica no fueron contundentes. Belaúnde ya había puesto en marcha algunas leyes para la protección de la industria local peruana. Después del golpe de Estado de Velasco, un intento de otro tipo de "tercera vía», la política económica peruana tampoco fue bien definida. La postura no fue del todo antiliberal sino fue sobre todo antiimperialista, refiriéndose a la influencia de Estados Unidos. Las exportaciones continuaron siendo el eje del desarrollo económico, pero las importaciones se controlaron con políticas proteccionistas. Aun así, el Perú no cerró del todo sus puertas al mercado externo. Prueba de ello fue que sus intercambios comerciales con Francia no decayeron. En pocas palabras, la diplomacia económica peruana al exterior se focalizó netamente en: velar por el incremento de las exportaciones y acrecentar el caudal de la inversión de capitales extranjeros. No pudo determinarse una política económica innovadora a largo plazo. Es por ello que, en el Ministerio de Relaciones Exteriores del Perú —antes llamado Ministerio de Relaciones y Culto-, no existió ningún centro especializado que sirviera de apoyo directo para desarrollar los intereses de una política económica peruana en Francia. Los únicos órganos que representaron los intereses de su diplomacia económica en el exterior fueron las embajadas y consulados. 


\section{Los ejes institucionales de la diplomacia económica franco-peruana}

\section{El rol de las Embajadas}

Después de haber recurrido a los fondos del Archivo del Ministerio de Relaciones Exteriores del Perú, así como a los del Archive Diplomatique du Ministère des Affaires Étrangères en Francia y del Centre d'Archives Économiques et Financières (CAEF) se ha constatado una vasta y diversificada correspondencia intercambiada. La importancia de la información brindada durante los Trente Glorieuses permitió poner en valor las funciones de las embajadas en materia política, económica y cultural. En cuanto a la diplomacia económica, se observó que ambas instituciones públicas cumplieron funciones similares más no equivalentes. Por el contrario, hasta podría afirmarse que cumplieron labores opuestas. ¿Acaso estas funciones tuvieron una relación directa con la condición de sus propias economías y el grado de su desarrollo? ¿Acaso sus disposiciones fueron producto de las relaciones Norte-Sur? Aunque el grado de interdependencia de las labores de los diplomáticos, altos funcionarios y empresarios fue inminente, cada uno contribuyó de manera independiente para dar forma a la diplomacia económica de su respectivo país.

Desde la Independencia del Perú, el inicio de las relaciones diplomáticas entre Perú y Francia se fundó bajo intereses netamente económicos y comerciales. Desde su creación, el Consulado General Francés en el Perú (1827) se focalizó en el desarrollo de relaciones económicas y comerciales donde los cónsules ejercieron labores diplomáticas múltiples basadas en asuntos de comercio y gestiones amistosas (Novak, 2005, pp. 43-44). Es así que, este órgano ha jugado un rol importante en el acercamiento de las relaciones diplomáticas franco-peruanas prestando un especial interés al ámbito económico y comercial.

La Embajada de Francia en el Perú se reactivó una vez finalizada la Segunda Guerra mundial. Aunque las funciones de los diplomáticos no fueron del todo suspendidas, desde 1944 se buscó una pronta y eficaz reanudación del contacto diplomático. Las relaciones culturales no fueron el eje de sus intereses. Sin embargo, este aspecto fue un tema de preámbulo en la gran parte de reportes en materia económica. Los «lazos históricos y tradicionales» entre ambos países fueron evocados indistintamente denotando una amistad franco-peruana de relevancia. Los diplomáticos franceses tuvieron tareas muy específicas según sus acreditaciones (embajadores, agregados y consejeros). La labor básica y elemental fue cubierta satisfactoriamente por cada uno de los miembros de la misión. Cabe señalar que las relaciones intelectuales fueron de gran importancia en el ámbito cultural. Algunos diplomáticos insistieron en la idea de que el incremento del intercambio de ideas sería un instrumento clave para acrecentar vínculos económicos entre Francia y Perú. 
Entre 1945-1975 las misiones científicas y culturales francesas enviadas al Perú se multiplicaron considerablemente. Al respecto, es oportuno mencionar el rol del arqueólogo e historiador Paul Rivet como intermediario para la gestión de un crédito financiero después del terremoto en el Cusco en 1950. El desembolso de 1 millón de francos de la Asamblea Nacional de Francia fue un hecho que se logró bajo las influencias particulares de este científico pro-americanista ${ }^{3}$. Por otro lado, la «Exposición de Tesoros del Perú» en 1957 en el Petit Palais de París tuvo una gran acogida. Este evento fue organizado por los peruanistas Bernard Flornoy y Louis Boudin con el fin de dar a conocer las riquezas culturales y arqueológicas del Perúu. Sin embargo, a pesar del entusiasmo y de las sendas muestras de una histórica amistad franco-peruana, el aspecto cultural influenció esporádicamente en los asuntos de la diplomacia económica francesa en el Perú.

Como resulta lógico, el cuerpo diplomático francés tuvo que cumplir algunas exigencias. Los enviados en misión debían tener un dominio de los asuntos con la región latinoamericana y especialmente con el Perú. Vista la importancia de la diplomacia económica para el Ministerio de Asuntos Exteriores en Francia, se comenzó a capacitar aún más a los agregados y consejeros comerciales. Estos debían cumplir una serie de funciones más allá de ser agentes informativos. Resulta curioso, pero el dominio de la lengua española no fue un requisito fundamental para los agregados o consejeros económicos. Sin embargo ellos debían estar muy involucrados con los intereses comerciales de Francia en el Perú. La vinculación y el contacto con las empresas peruanas tuvo que ser establecida por los agregados comerciales quienes daban cuenta exacta de sus labores.

En este sentido, los temas privilegiados giraron en torno a las relaciones económicas, comerciales, financieras y de cooperación técnica. Los especialistas debían estar en la búsqueda constante de posibles inversiones, evaluar los sectores y calcular los riesgos respectivos. Se abocaron a investigar y a estudiar cercanamente los negocios en proyección. Fueron los primeros en plantear las recomendaciones y proposiciones para la participación a las convocaciones de diversas licitaciones y adjudicaciones. Por ende, cumplieron un rol propositivo y dinámico. Los viajes al interior del país también fueron parte del programa de sus actividades. La visita a las ciudades y lugares estratégicos de la economía peruana fueron parte de la misión de la expansión económica francesa.

\footnotetext{
3 «Donativo de la Asamblea Francesa pro-víctimas del terremoto del Cusco. Mensaje de agradecimiento por el generoso gesto de donar un millón de francos para auxiliar a las víctimas del terremoto del Cusco, haciendo extensivo este agradecimiento al Sr. Diputado Paul Rivet, autor de la iniciativa», n 5-14-A / 232, Archivo Central MRE, París, octubre de 1950, p. 1-2.

4 «Llegada del material propaganda Exposición peruana en París», n 5-14-A/117, Archivo Central MRE, París, mayo de 1958, p. 1.
} 
El rol del cuerpo diplomático francés en Perú cumplió una tarea fundamental: la expansión de la economía francesa. Para tal objeto, los embajadores y sobre todo los agregados comerciales estuvieron en la búsqueda de nuevas inversiones. Ellos se esforzaron para incrementar los intercambios económicos tratando de mantener el equilibrio de su balanza comercial con el Perú. En este sentido, controlaron o frenaron el ritmo de sus importaciones. Por lo tanto, los diplomáticos tuvieron la misión de informar y recomendar a los altos funcionarios del Quai d'Orsay y de la Direction des Relations Económiques Etrangères para que solo con la aceptación de estos dos se pudieran ejecutar las decisiones. Cabe notar que los consejeros comerciales fueron hombres de negocios expertos en la economía peruana. Dentro de sus funciones también estuvo el hecho de evaluar los posibles acuerdos comerciales, aduaneros y financieros. Los agregados militares también formaron parte de los objetivos de la diplomacia económica francesa en Perú. Por tal razón, ellos no solo fueron encargados de mantener la influencia en este dominio, sino que también debían encargarse de la venta de material militar para el incremento de sus intercambios económicos. Por otro lado, el cuerpo diplomático francés también fue un intermediario entre su gobierno con las empresas francesas interesadas en el Perú y las empresas peruanas interesadas en exportar hacia Francia.

A pesar de contar con un personal altamente calificado y exigente, los agregados y consejeros comerciales franceses en Perú enfrentaron el gran reto propio de la post-guerra: la competencia agresiva de otras naciones. A pesar de haber estado bien organizados, los diplomáticos franceses no fueron los únicos en tener la visión de expandir sur influencias económicas en el Perú. Los estadounidenses, los alemanes, los japoneses, los suizos y los belgas fueron, entre muchos otros, algunos de los rivales de Francia en el Perú.

La representación diplomática del Perú en Francia se dio una vez instaurada la representación de Francia en el Perú (1827). El rango de la Legación del Perú en Francia fue elevada a la de Embajada en 1945. En esta misma ocasión, se elevaron de rango a otras diecinueve naciones, entre ellas cinco latinoamericanas: México, Colombia, Chile, Venezuela y Paraguay 5 . El cumplimiento de las funciones de las misiones diplomáticas peruanas estuvo íntimamente ligado a la organización de los gobiernos y sus respectivas políticas exteriores caracterizadas por su ambigüedad. En ese sentido, es necesario tomar en cuenta que la falta de una política económica a largo plazo desestabilizó el buen rendimiento de las funciones de los representantes peruanos en Francia. Esa desorganización se pudo notar claramente a través de la correspondencia diplomática examinada. Los reportes no fueron clasificados temáticamente sino más

«Embajadas francesas», n -5-14-A / 199, Archivo Central MRE, París, abril de 1948, p. 1. 
bien se trató de un cúmulo de informes o relatos redactados a la orden del día. Por lo tanto, la función básica y fundamental del cuerpo diplomático como «agente informativo» fue por demás una tarea cumplida.

Los temas de interés en materia de diplomacia económica se evocaron a la condición de la vida francesa, al estado de la economía y al comercio, a la política interior y al rol de Francia en las relaciones internacionales. Cabe resaltar que la fuente más consultada por los diplomáticos fue la de la prensa escrita. Los periódicos y revistas como Le Monde, Le Figaro, La Tribune des Nations y La documentation française fueron consultados regularmente. Otra función estuvo ligada con el hecho de recomendar o alertar aspectos de la economía francesa que pudieran ser de interés directo para el gobierno peruano. Aunque pocas veces se pudo notar que los agregados comerciales realizaran estudios de mercado para la venta de productos peruanos, raramente los embajadores se interesaron en desarrollar los intercambios comerciales. Así, no se pudo apreciar un interés firme en cuanto a la inserción de la presencia económica peruana en Francia.

El perfil de los diplomáticos peruanos en Francia comprendió ciertas características. Los criterios básicos de conocer y estar relacionados con la cultura de un determinado país se afinaron de manera elocuente con la francofonía. Sin embargo, la francofilia también fue un elemento de importancia. En este aspecto cabe recalcar que, la influencia de la francofilia en la sociedad peruana aristócrata todavía era una realidad claramente apreciable a pesar de las influencias anglosajonas y sobre todo norteamericanas cada vez más imponentes. La carrera diplomática peruana comenzó de manera oficial en 1956 después de la apertura de la Academia Diplomática del Perú. No obstante, incluso después de su apertura, los diplomáticos más destacados eran parte de la élite aristócrata peruana, sobre todo limeña. Los diplomáticos enviados a Francia muchas veces fueron personajes de la élite intelectual, políticos o expolíticos y hombres de notables familias relacionadas con la vida empresarial del país ${ }^{6}$. Sin embargo, no faltó ocasión donde algunos designados por favores políticos terminaran cumpliendo roles improvisados.

En el campo de la diplomacia económica la Embajada Peruana en Francia tuvo un rol mucho más pasivo y poco ambicioso ante su homólogo. Durante los Trente Glorieuses el reforzamiento de los intereses económicos peruanos en Francia no siguieron una continuidad bajo órdenes oficiales definidas. Por ende, las funciones del cuerpo diplomático tampoco fueron del todo precisas. Muchas veces se notó que los agregados y los embajadores no supieron diferenciar ni definir sus funciones

\footnotetext{
6 Por ejemplo en 1948 el cuerpo diplomático peruano en Francia estuvo conformado por: Arturo García Calderón, Carlos Mackehenie, Enrique Peńa Barrenechea, Javier Pérez de Cuellar y el Coronel César Egúsquiza Vidal. «Integrantes de la Cancillería», n -5-14-A / 46, Archivo Central MRE, París, 5 de febrero de 1948, p. 1.
} 
cabalmente. El cuerpo diplomático peruano en Francia estuvo mayormente a la espera de las propuestas francesas. Muy raras veces se llevó a cabo una promoción de productos peruanos y perdieron oportunidades para explotar al máximo esos lazos de amistad tradicionales e históricos. Sin embargo, tales puntos de flaqueza tuvieron sus propias razones existenciales.

Desde 1950, la demanda de información sobre el Perú en la Embajada del Perú en Francia se multiplicó contundentemente. Tanto los funcionarios franceses como los empresarios se interesaron cada vez más en acrecentar sus inversiones en el Perú. Cabe notar que los boletines de información sobre el Perú con los cuales se contaba en las décadas de 1950 y 1960 estaban desactualizados. Los diplomáticos peruanos exigieron, constantemente, el envío de material de publicidad renovado y de calidad. Sin embargo, estas exigencias no fueron atendidas satisfactoriamente. Por otro lado, también fue posible constatar que esta embajada sufrió de carencias presupuestarias. Las quejas sobre un personal muy reducido para las múltiples funciones a cumplir fueron puestas en evidencia. Es importante tomar conciencia de tales dificultades y obstáculos pues solo así se puede comprender de manera amplia el contexto por el cual la diplomacia económica peruana careció de los medios necesarios para instaurarse de mejor manera en Francia. Siendo la embajada un órgano supeditado del Gobierno peruano los límites de sus funciones invitan a una reflexión en este dominio.

\section{El rol de las cámaras de comercio}

Desde 1946, la Chambre de Commerce France-Amérique latine ha sido un instrumento muy importante para el acercamiento de las relaciones comerciales entre Francia y Latinoamérica. Los boletines publicados a nombre de esta cámara de comercio brindaron una información sintética pero bien elaborada de las diferentes posibilidades de negocio. Se debe recordar que el Perú no fue un país privilegiado para Francia como lo fue Brasil, Argentina y México. Sin embargo, Francia tampoco ignoró o menospreció las ventajas que el Perú podía ofrecer en el ámbito económico. En 1955, un artículo extenso intitulado "L'économie d'un grand pays: Le Pérou» sirvió como una guía de comercio para negociar e invertir en este país. En esta ocasión, el embajador de Perú en Francia señor Luis Solari, manifestó claramente como la tradicional amistad franco-peruana así como sus relaciones espirituales y culturales daban lugar a una nueva era en el reforzamiento de las relaciones entre estos dos países. Enseguida, se admitió que la presencia financiera e industrial francesa en el Perú era un hecho rotundo que tendría repercusiones favorables en los intercambios comerciales entre ambos países. De hecho, en septiembre de 1955 un contrato entre la Corporación del Santa se concretizó con el Banco de París y de los Países Bajos, la firma francesa Delattre et Frouard Réunis y la Sociedad General d'Explotaciones 
Industriales de Francia. Tal contrato celebró la futura construcción de la fábrica siderúrgica en Chimbote y la Central Hidroeléctrica del Cañón del Pato (Chambre de Commerce France-Amérique Latine, 1955, p. 7). En este sentido la Cámara de Comercio Francia-América latina sirvió como un medio de difusión tanto informativo como propositivo para el examen de nuevas inversiones francesas en el Perú.

La creación de la Cámara de Comercio e Industria Peruano-Francesa (CCIPF) fue el resultado de la labor del cuerpo diplomático francés en el Perú. A la luz de su política exterior, la instalación de puestos de expansión económica de Francia también instauró su sede en Lima. Esta cámara de comercio fue creada en abril de 1945 bajo la iniciativa del embajador francés en el Perú, señor Maurice Dayet. Así, el estatuto de la Cámara de Comercio Francesa en el Perú fue establecido. El primer comité estuvo conformado por las personalidades más reconocidas de la pequeña colonia francesa en Lima. Los hombres de negocios más notables e involucrados en asuntos comerciales con el Perú fueron también los promotores de esta nueva red económica ${ }^{7}$. Sus objetivos trazados inicialmente se basaron en promover el desarrollo del comercio, de la industria y de todos los negocios franceses en Perú (Varese, 1945, pp. 3-4). Por lo tanto, en un inicio se forjaron sobre todo los intereses económicos franceses. Sin embargo, se comprendió que una cooperación institucional francoperuana debía ser el paso más apropiado. De esta manera, los sectores comerciales, industriales, agrícolas y económicos, no solo de uno sino de ambos países, debían ser representados ante el Estado y las empresas privadas. Fue así como se dio origen a la CIIPF teniendo como objetivo mayor el de acrecentar el comercio franco-peruano.

\section{Los instrumentos de apoyo para un acercamiento de la diplomacia económica bilateral}

\section{Los acuerdos financieros franco-peruanos}

Pese al rol multilateral del Acuerdo General sobre Aranceles Aduaneros y Comercio (GATT), Francia y Perú dieron muestras de iniciativas bilaterales para el incremento de sus intercambios comerciales. Al respecto, un acuerdo comercial con el Perú fue examinado por una comisión francesa en el Perú en 1947. Este debía ser elaborado

\footnotetext{
7 El primer comité de la Chambre de Commerce française de Lima estuvo formada por Edouard Ferrand nombrado presidente. El señor Ferrand era considerado como la personalidad francesa más importante de Lima en materia comercial. Asimismo, Gustave d'Auriol, director de la compañía francesa Mines de Huaron, fue nombrado vicepresidente; Gilbert Caron, representante de la Casa Harth, considerada como la misión de comercio francés más importante en Lima, fue nombrado tesorero; y, Jean Delaunay, un hombre de negocios reputado, fue nombrado secretario. "Chambre de Commerce Française de Lima», lettre n 1, M. Dayet, Ministre de France au Pérou à son Excellence M. le Ministre des Affaires Étrangers à París, Série B-95-1 Amérique, Pérou (14) Questions économiques 1944-1952, AMAE, Lima, 2 de enero de 1945, p. 1.
} 
bajo la "cláusula de la nación más favorecida» pero esta idea se bloqueó por la inestabilidad política que el Perú atravesaba en ese año ${ }^{8}$. Otro intento se llevó a cabo en 1956, pero una vez más este proyecto fue abortado. Después de la adhesión del Perú al GATT, los acuerdos comerciales bilaterales y la renovación de estos fue prohibida de manera automática' . Tanto Francia como Perú, al ser miembros de este organismo multilateral, fueron limitados en cuanto a políticas aduaneras y comerciales bilaterales.

Sin embargo dos acuerdos de pagos se llevaron a cabo. En 1946 se puso en marcha un acuerdo de pagos en una moneda nueva: libras esterlinas. Este acuerdo fue propuesto por la escasez de dólares en el Perú contrarias a sus reservas monetarias superiores en libras esterlinas. La carencia financiera en dólares, frenó las importaciones peruanas y algunos productos franceses fueron afectados. Por tal razón Francia propuso tal acuerdo de pagos bajo la supervisión del Reino Unido ${ }^{10}$. Los resultados fueron óptimos para Francia y desde 1947 la balanza comercial franco-peruana se fue equilibrando. Sin embargo, solo se trató de una medida temporal y pocos años después el pago en esta moneda se fue tornando poco ventajoso para ambos países. Paralelamente, otro acuerdo fue examinado. El Banco de Crédito del Perú y el Banco de Francia apostaron por un acuerdo de pagos en francos franceses ${ }^{11}$. A pesar del conflicto interno que este acuerdo ocasionó entre las entidades y diplomáticos franceses, el acuerdo de pagos franco-peruano fue dado en vigor en 1950. A solo unos meses de su uso, las críticas ya eran varias y a pesar de las contradicciones este acuerdo duró cinco años sin haber cubierto las expectativas deseadas ${ }^{12}$.

\section{La Feria de Exposición francesa en Lima}

Esta feria se llevó a cabo en septiembre de 1957. Se trató de otro ejemplo del acercamiento en materia de diplomacia económica entre Perú y Francia. Las relaciones comerciales, financieras e industriales conocieron un nuevo impulso. El Gobierno francés eligió como sede de su primera feria de exposición en América Latina a la

\footnotetext{
8 «Télégramme», $\mathrm{n}^{\circ}$ 98, envoyé par M. Ledoux Ambassadeur de France au Pérou aux Bureau des Affaires Étrangères, Série B-95-1 Amérique, Pérou (14) Questions économiques 1944-1952, AMAE, Lima, 20 mai 1947, p. 1.

9 "Négociation d'un accord commercial», lettre n 326/ AM, Leon Brasseur, Ambassadeur de France au Pérou à son Excellence M. le Ministre des Affaires Etrangères, Direction des Affaires Économiques et Financières, B-0061 432/1, Archives CAEF, París, 1956, p. 1.

10 «Relations économiques franco-péruviennes», lettre n 1965, Direction des Finances Extérieures, B-0061 432/1, Archives CAEF, París, 17 de diciembre de 1946, p. 1.

11 "Note sur les relations financières entre la France et le Pérou», Rapporteurs M. Norcy et Théron. Mission de la Banque de France en Amérique du Sud, B-0061 432/1, Archives CAEF, 2 mai 1950, p. 1-3. Véase también: «Relations économiques franco-péruviennes», lettre n 1965, Direction des Finances Extérieures, B-0061 432/1, Archives CAEF, París, 17 de diciembre de 1946, p. 1.

12 "Accord de paiement franco-péruvien", lettre n 941, J. Cottier, Inspecteur des Finances Chargé de mission à M. le Ministre de Finances et des Affaires Économiques D.R.E.E., Série B-95-1 Amérique, Pérou (14) Questions économiques 1944-1952, AMAE, Lima, 25 février 1951, p. 3.
} 
ciudad de Lima. Esta elección fue basada en la coyuntura económica favorable por la cual atravesó el Perú. Durante la década de 1950, este país fue considerado como uno de los países latinoamericanos más liberales. Por ende, los capitales franceses podrían encontrar gran acogida. La presencia de 500 firmas francesas fue prevista para tal evento $^{13}$. Las firmas más famosas de la industria francesa estuvieron presentes para la exposición de sus productos de exportación de una manera espectacular e inédita como fue el caso para la exposición del material militar ${ }^{14}$.

Fruto de la política de expansión económica del Gobierno francés, esta feria buscó el reforzamiento directo de las relaciones económicas con el Perú. Por otro lado, el Perú fue invitado en diversas oportunidades para participar en ferias de difusión de productos de exportación en Francia. La Feria de París invitó de manera regular al Gobierno peruano en 1963, 1965 y $1968^{15}$. Asimismo, el Perú fue invitado a participar en el Salón Internacional de la Alimentación en 1965 y $1966^{16}$. En definitiva, a pesar de ser grandes oportunidades para la exposición de productos peruanos, estas invitaciones no fueron siempre aceptadas. El gran obstáculo se centró en la falta de un presupuesto destinado para preveer y ejecutar tal desplazamiento.

\section{Dos visitas de importancia: Manuel Prado y Charles de Gaulle}

Las visitas presidenciales en 1960 y 1964 realizadas por el presidente Manuel Prado y el general Charles de Gaulle respectivamente, no solo permitieron consolidar las relaciones en el ámbito político. Tanto la doctrina Prado como la doctrina de la latinité de C. De Gaulle encerraron el ejemplo de la voluntad de un reforzamiento diplomáticoeconómico entre ambos países. Incluso, desde una perspectiva más amplia, ambos desplazamientos fueron producto y buscaron extender aún más el acercamiento cultural pero sobre todo económico entre Europa y América Latina. Después de haber suspendido su visita inicial en razón de la guerra en Argelia en 1958, M. Prado realizó su «viaje de amistad» a Europa en febrero de $1960^{17}$. Este presidente tuvo sin duda una inclinación francófila. La visita del presidente Prado fue vista como un

\footnotetext{
13 «Remite un artículo de France-Soir del 19 de octubre de 1956 intitulado Francia prepara una gran exposición en el Perú», Cote: $\mathrm{n}^{\circ}$ 5-14-A/263, Archives MREP, París, octubre de 1956, p. 1.

14 «La exposición industrial francesa», Cote: n 5-14-A/169, Archives MREP, París, agosto de 1957, p. 1; Véase también: «Material militar que será expuesto», n 5-14-A/198, Archivo Central MRE, París, setiembre de 1957, p. 1. 15 «Invitación al Perú a participar en la Feria de París», n 5-14-A/77, Archivo Central MRE, París, febrero de 1962, p. 1; Véase también n 5-14-A/9, París, 15 de febrero de 1965, p. 1; n 5-14-A/147, París, 21 de setiembre de 1967, p. 1; n 5-14-A/125, París, 30 de abril de 1969, p. 1 (Archivo Central MRE).

16 «Invitación a participar en el Salón Internacional de la Alimentación», n 5-14-A/121, Archivo Central MRE, París, 3 de diciembre de 1965, p. 1.

17 «Voyage en France de M. Prado», lettre n 443, Albert Ledoux, Ambassadeur de la France au Pérou à son Excellence M. Robert Schuman, Ministre des Affaires étrangères à París, Direction d'Amérique, Série B-Amérique, Pérou (11), Questions économiques, AMAE, Lima, le 29 septembre 1946, p. 1.
} 
símbolo de la unión entre el continente europeo y latinoamericano. En cuanto a las relaciones franco-peruanas, la visita presidencial despertó mucho interés no solo ante las autoridades francesas sino también ante la prensa. Prado fue considerando como un «inmejorable amigo de Francia» y prueba de ello fue su residencia en ese país después de su exilio hasta su fallecimiento (1962-1967) (Novak, 2005, pp. 227-228).

La gira en Europa buscó sin duda una alternativa económica frente a la dependencia creciente del Perú ante Estados Unidos. Poco después de su regreso a Perú, Prado manifestó que su viaje había comprendido un éxito político, diplomático, económico y cultural. Sin embargo, el énfasis central fue dado en sus logros en materia económica y financiera. El presidente justificó su desplazamiento, criticado por la oposición, con los fines netamente económicos que lo motivaron. Insistió en dar precisiones sobre las ofertas concretas y ventajosas logradas con los países europeos que permitirían acelerar el desarrollo económico del Perú. M. Prado visitó Francia entre el 15 y 18 de febrero de 1960. Después de sus entrevistas protocolares se examinó la posibilidad de créditos franceses para la construcción de centrales hidroeléctricas y térmicas así como para la extensión de las instalaciones siderúrgicas de Chimbote ${ }^{18}$. Después de la visita del presidente, una gran lista de precontratos fue firmada por el exministro de Trabajos Públicos del Perú, presidente del Banco Minero y a su vez hombre de confianza de M. Prado, M. Hilbeck, en París. La primera realización de esa lista, la cual solo se concluyó parcialmente, fue la compra de cinco helicópteros Alouette II por el grupo peruano Panindustria y el Ministerio de Aeronáutica del Perú19.

En febrero de 1961, el presidente Charles de Gaulle fue homenajeado por los veinte jefes de misión de América Latina acreditados en París. En esta ocasión, de Gaulle pronunció una alocución en la cual subrayó enfáticamente los lazos históricos que unían Francia y América Latina. Así entre setiembre y octubre de 1964 el viaje de uno de los presidentes más populares de Francia, al menos durante esos años, se llevó a cabo en la región. C. de Gaulle visitó el Perú del 25 al 28 de setiembre de ese año. Su discurso desde el Palacio municipal, su visita al Centro de Instrucción Militar Peruano, su visita al Colegio Franco-Peruano y su entrevista con el presidente Belaúnde fueron parte de un programa basado en el reforzamiento de las relaciones culturales, militares, políticas y, por supuesto, también económicas ${ }^{20}$.

\footnotetext{
18 «Message du Président Prado sur son voyage en Europe», Pierre Lefort, Conseiller commercial auprès de l'Ambassade de France au Pérou à M. le Ministre de Finances et des Affaires Économiques, Direction des Relations Économiques Etrangère, B-0061 432/1, Archives CAEF, París, 31 de marzo de 1960, pp. 1-2.

19 «Commande de 5 hélicoptères Alouette. Contrat Interetud-Sud-Aviation», lettre n 1362, Pierre Lefort, Conseiller commercial auprès de l'Ambassade de France au Pérou à M. le Ministre de Finances et des Affaires Économiques, Direction des Relations Économiques Etrangère, B-0061 432/1, Archives CAEF, París, 9 juin 1960, p. 1-3.

20 Consultado el 25 de marzo de 2017: http://www.charles-de-gaulle.org/pages/l-homme/dossiers-thematiques/ de-gaulle-et-le-monde/de-gaulle-et-1-amerique-latine/reperes/chronologie-des-relations-entre-la-france-et-1amerique-latine.php
} 
El Perú ejemplificó de manera reveladora el impacto de la visita de C. de Gaulle a América Latina. Esta visita se desarrolló en un ambiente favorable en búsqueda del desarrollo de relaciones económicas y financieras franco-peruanas. Es así que, una lista de proyectos a largo y a corto plazo fue examinada entre ambos países con motivo del viaje del mandatario francés. Esos proyectos se concentraron sobre los sectores fuertes de la ingeniería francesa: la industria petrolera y parapetrolera, los trabajos de hidráulica, de aducción y de distribución de aguas y los transportes. Del mismo modo, los grandes trabajos de abastecimiento de equipamiento pesado (turbinas, locomotoras, aviones) y material militar (helicópteros, aviones, tanques) fueron cuidadosamente examinados. Estos sectores representaron los puntos fuertes y puntos débiles de la presencia económica francesa no solo en Perú sino en toda América Latina. La reputación de Francia como un gran país exportador de servicios fue sin duda ratificada después del viaje de C. de Gaulle (Barjot y Cayo Durand, 2014, pp. 194-195).

Dichos proyectos dieron prueba del interés mutuo en materia de diplomacia económica. Francia buscó participar en el desarrollo económico del Perú. Ambos países desearon acrecentar de manera rápida y equilibrada sus intercambios comerciales para lo cual la estabilización de los precios de los productos de base era indispensable $^{21}$. Las advertencias del consejero comercial Pierre Lefort donde insistió en que la política económica del Perú era "extremadamente imprecisa», ya anunciaban que, como fue en el caso de M. Prado ańos antes, a lo mejor no todos los proyectos se concluirían $^{22}$. Sin embargo, como fruto de ese viaje, las relaciones militares francoperuanas conocieron un nuevo impulso. Tanto en 1967 como en 1969 la compra de material militar por el Ministerio de Aeronáutica del Perú fue el ejemplo claro del rol que jugó la diplomacia económica entre ambos países. Por otro lado, otro aspecto que conoció una nueva etapa de reforzamiento fue el de la cooperación técnica. De hecho el Centro de Cooperación Técnica Franco-Peruana creado en 1957 estuvo destinado a la formación de especialistas de la electricidad y la mecánica. Después de la visita del presidente francés, este centro fue dotado con más instrumentos de trabajo para la sección de electromecánica y de motores para centrales hidroeléctricas. Del mismo modo, una nueva misión de expertos, profesores franceses sería nuevamente enviada con el fin de continuar con sus labores de enseñanza ${ }^{23}$.

\footnotetext{
21 «Communiqué franco-péruvien», Télégramme n 179, B-0061 432/1, Archives CAEF, Lima, le 1"er octobre 1960, p. 2.

${ }^{22}$ Lettre $^{\circ}$ 2035, M. Pierre Lefort, Conseiller commercial auprès de l'Ambassade de France au Pérou à M. Le Directeur de l'A.S.M.I.C., B-0061 432/1, Archives CAEF, Lima, 14 août 1964, p. 3.

23 «Communiqué franco-péruvien», Télégramme n 179, B-0061 432/1, Archives CAEF, Lima, le $1^{\text {er }}$ octobre 1960, p. 3.
} 
Las consecuencias inmediatas de la política económica después del golpe de Estado de Velasco Alvarado fueron alarmantes para Francia. El carácter nacionalista limitó las importaciones peruanas y por lo tanto el intercambio comercial con Francia también resultó afectado. A pesar del impacto ocasionado por el régimen revolucionario, la compra de material militar incrementó las exportaciones francesas en 1969. Es así que, el intercambio comercial no fue promovido significativamente, pero este tampoco fue interrumpido radicalmente. A pesar de las compras ocasionales, el ritmo de crecimiento de los intercambios comerciales no disminuyó. Sin embargo a causa de la limitación de las importaciones peruanas, la balanza de pagos se equilibró a favor de Francia desde 1974. Por otro lado, la política antiamericanista impartida por Velasco dio esperanzas para acrecentar las relaciones político-diplomáticas entre ambos países. Entre 1973 y 1975 las relaciones diplomáticas fueron suspendidas a causa de ensayos nucleares en el océano Pacífico. Sin embargo este enfriamiento diplomático no afectó casi en nada al desempeño de las funciones informativas o de expansión en materia económica entre ambos países. En un reporte de la Embajada de Perú en Francia se remarcó que la ruptura diplomática entre estos dos países «no había afectado en las relaciones de carácter comercial ${ }^{24}$. El fin de los Trente Glorieuses como producto del impacto nefasto de los shocks petroleros en 1973 y 1979 también afectó a las relaciones franco-peruanas en todos los dominios. Sin embargo, el reforzamiento de las relaciones en el ámbito de la diplomacia económica continuó evolucionando.

\section{Conclusiones}

La diplomacia económica jugó un rol desigual en las relaciones bilaterales franco peruanas durante los Trente Gloriueses. Al analizar dos países de diferente condición económica, es posible notar que las funciones de las instituciones fueron disímiles. Existió un desnivel en la representación de sus estructuras. La eficiencia de sus tareas dependió de factores de orden político y económico pero sobre todo del grado de organización institucional que estos manejaron en cada país.

Los agregados y consejeros comerciales franceses en Perú estuvieron mucho más capacitados y especializados en materia económica. Los reportes, notas de síntesis y los estudios de mercado de ambas embajadas estuvieron focalizados en metas opuestas. De una parte, el cuerpo diplomático francés promovió la extensión de la influencia económica francesa en el Perú, y por otra, el cuerpo diplomático peruano buscó o esperó la inversión francesa para desarrollar los intereses económicos peruanos.

\footnotetext{
24 «Ref. Artículo Le Monde, Adquisiciones Mirage V», n 5-14-A / 183, Archivo Central MRE, París, 2 de octubre de 1973, p. 1.
} 
No obstante, ambos intereses se fusionaron a causa de sus beneficios mutuos. Tanto Francia como Perú estuvieron focalizados en aumentar el flujo de sus intercambios comerciales. Una interdependencia de objetivos económicos hizo que ambos Estados continuaran reforzando sus lazos en el dominio de la diplomacia económica. El estudio de tres décadas de relaciones mostró ejemplos concretos de un verdadero reforzamiento. Acercamiento que también conoció sus propios límites, sus obstáculos y sus deficiencias por ambas partes. Sin embargo, los esfuerzos no fueron suficientes para que Francia y Perú fueran considerados socios estratégicos de primer orden en materia económica.

\section{Referencias}

Badel, L. (2010). Diplomatie et grands contrats: l'état français et les marchés extérieurs au XXe siècle. París: Publications de la Sorbonne.

Barjot, D. Lescent-Giles, I. y De Ferriere Le Vayer, M. (eds.) (2002). L'Américanisation en Europe au XXe siècle: économie, culture, politique. Lille: Centre de Recherche sur l'Histoire de l'Europe du Nord-Ouest y Université Charles de Gaulle-Lille.

Barjot, D., Cayo Durand, G. (2014). Les échanges économiques entre la France et l'Amérique latine pendant la présidence du géneral de Gaulle: une première approche. En M. Vaïsse (dir.), De Gaulle et l'Amérique latine. Rennes: Fondation Charles de Gaulle y Presses universitaires de Rennes. https://doi.org/10.4000/books.pur.42546

Carron de la Carriere, G. (1998). La Diplomatie économique: le diplomate et le marché. París: Económica.

Chambre de Commerce France-Amerique Latine (1955). L'économie d'un grand pays: le Pérou. Revue de la Chambre de Commerce France-Amérique latine, IX (5).

Fourastie, J. (1979). Les trente glorieuses: ou la Révolution invisible de 1946 à 1975. París: Fayard.

Morillas Gómez, J. (2000). La diplomacia económica. La otra mediación del Estado en el Mercado. Boletín Económico del ICE, nº 2664.

Novak, F. (2005). Las relaciones entre Perú y Francia (1827-2004). Lima: Instituto de Estudios Internacionales de la Pontificia Universidad Católica del Perú.

Nye, J. (2004). Soft power: The means to success in world politics. Nueva York: Public Affairs.

Sánchez Castejón, P. (2013). La diplomacia comercial en el centro de la diplomacia económica española. Anuario Jurídico y Económico Escurialense, 46.

Sheahan, J. (2001). La economia peruana desde 1950: buscando una sociedad mejor. Lima: Instituto de Estudios Peruanos.

Thorp, R. y Bertram G. (2013). Perú 1890-1977: crecimiento y políticas en una economía abierta. Lima: Universidad del Pacífico.

Varese, R. (1945). Cámara de Comercio Francesa del Perú. Estatutos, Lima. 


\section{Fuente Archivística}

\section{Archivo Diplomático. Ministerio de Asuntos Exteriores de Francia (AMAE)}

A/ Serie B-95-1 América, Perú (14) Cuestiones económicas 1944-1952

-Carta $n^{\circ} 1$, Lima, 2 de enero de 1945.

-Carta ${ }^{\circ}$ 416, Lima, 6 de febrero de 1950.

-Telegrama, nº 98, Lima, 20 de mayo de 1947.

-Carta n ${ }^{\circ}$ 941, Lima, 25 de febrero de 1951.

B/ Serie B-95-1 América, Perú (11) Cuestiones económicas 1944-1952

-Carta n 443, Lima, 29 de setiembre de 1946.

\section{Archivo Central del Ministerio de Relaciones Exteriores del Perú (MRE)}

N 5-14-A/ 199, París, abril de 1948.

N 5 -14-A/ 46, París, 5 de febrero de 1948.

N 5 -14-A/ 232, París, octubre de 1950.

N 5-14-A/ 263, París, octubre de 1956.

$\mathrm{N}^{\circ}$ 5-14-A/169, París, agosto de 1957.

$\mathrm{N}^{\circ}$ 5-14-A/198, París, setiembre de 1957.

$\mathrm{N}^{\circ}$ 5-14-A/117, París, mayo de 1958.

$\mathrm{N}^{\circ}$ 5-14-A/77, París, febrero de 1962.

N 5 5-14-A/9, París, 15 de febrero de 1965.

$\mathrm{N}^{\circ}$ 5-14-A/121, París, 3 de diciembre de 1965.

N ${ }^{\circ}$ 5-14-A/147, París, 21 de setiembre de 1967.

$\mathrm{N}^{\circ}$ 5-14-A/125, París, 30 de abril de 1969.

N 5-14-A/ 183, París, 2 de octubre de 1973.

\section{Centro del Archivo Económico y Financiero de Francia (CAEF)}

Caja B-0061 432/1

-Carta n ${ }^{\circ}$ 1965, París, 17 de diciembre de 1946.

-Carta n 326/AM, París, 1956.

-Carta n AM, París, 31 de marzo de 1960.

-Carta n 1362, París, 9 de junio de 1960.

-Telegrama ${ }^{\circ}$ 179, Lima, 1 de octubre de 1960.

-Carta n ${ }^{\circ}$ 2035, Lima, 14 de agosto de 1964.

Fecha de recepción: 27 de abril de 2017 Fecha de aprobación: 30 de mayo de 2017 